\title{
Introduction
}

\section{Information Science meets Philosophy: Information, Knowledge, Autonomous Action, and Big Data}

\author{
Daniel Martínez-Ávila \\ Sao Paulo State University (UNESP), Brazil \\ E-mail: martinez.avila@unesp.br
}

The history of Information Science is marked by the contributions and influence of scholars and theories from several fields, including Sociology, Communication, Linguistics, Philosophy, and others. Among all of them, Philosophy is arguably one of the most obvious ones and also many times unrecognized and overlooked. While some of the faculty and researchers in Information Science have good credentials in Philosophy, debates between fields and incursions of scholars are not so common. One notable exception is Floridi's proposal of "Philosophy of Information" (2002) and the discussions/rebuttals that followed, mainly in the Information Science field, such as Herold (2004) and of course the recent special issue of Education for Information on Philosophy of Information (Dineen, 2017). Although not the focus of the present text, the questions remain here: how is the concept of information the center of (a) Information Science while philosophers and other scholars have been studying the concept of information for many years in different fields? What dialogues between the fields in this regard are not being heard? To illuminate this dialogue, the departments of Philosophy and Information Science of Sao Paulo State University (UNESP), in Brazil, have been organizing the international EIICA Conferences on Information, Knowledge, and Action, in which scholars from these two and other fields present their research and interests. The $10^{\text {th }}$ edition of the Conference was held between June 18-22, 2018, with the theme "Information, Knowledge, Autonomous Action, and Big Data: Continuity or Revolution?", as part of the project "Understanding opinion and language dynamics using massive data", granted by the 2016 Digging into Data Challenge of the Trans-Atlantic Platform for Social Sciences and Humanities.

The following papers have been selected among the contributions to the conference and are a sample of the diversity of backgrounds and perspectives that were present at the meeting. Technological, sociological, ethical, theoretical, and methodological challenges were discussed not only by scholars from Information Science and Philosophy, but also from Linguistics, Communication, Computer Science, and more. In this sense, these papers discuss aspects related to race, digital rights, languages, dystopias, social interactions, and others from the different points of view 
of their authors and also considering the input and discussions of such a diverse audience.

Renato Souza's paper sums up long running debates about "Algorithms, future and digital rights". He reviews some of the characteristics of the current technologies and their algorithms and discusses their implications for our digital rights. While the ethical reflections on technologies within Computer Science, à la Richard Stallman (e.g., 2015), are rare and increasingly necessary, Renato Souza addresses many of these questions and posits ideas for guiding the imminent future in Computer and Information Science. From the point of view of Communication and Media studies, Vinicius Romanini, Rebeka F. Guarda and Marcia P. Ohlson offer a discussion about the dystopic political scenario left by technologies and big data in their paper "Disinformation, dystopia and post-reality in social media: a semiotic-cognitive perspective". Concepts such as "fake news", "alternative facts", "post-truth", and "post-reality" in the "global village" are discussed through the lenses of Peircean semiotics. The authors work with concepts by Peirce, such as belief, mental habits, controlled action, final opinion, truth and reality, and scientific method, to counteract the dystopia created by disinformation, social networks, and big data. Mariana Vitti Rodrigues and Maria Eunice Quilici Gonzalez, in their paper "Semiotic information in data-driven societies: Where are we heading to?", also explore the application of Peircean semiotics and its ethical and aesthetic principles to complex problems of data-driven societies. Drawing on an interdisciplinary approach, this paper discusses the challenges of Information and Communication Technologies for science, politicians, educators, philosophers, and, as the authors put it, anyone concerned with the role of information in autonomous action. Well-versed in sociolinguistics, José L. Magro, in his paper "Resistance identities and language choice in Instagram among Spanish urban artists in Da DMV: Big Data and a mixed-method", addresses some methodological problems of big data. As big data has been linked to the latest scandals of political elections worldwide, and politics is always connected to social issues such as racism, discrimination, and oppression, Magro's paper can be framed within another important aspect of the era of big data: the political consequences and uses of big data to reinforce hegemonic ideologies and the categorization and stigmatization of minorities. Finally, Claudia Wanderley's paper titled "Oral cultures and multilingualism in a world of Big digital data: the case of Portuguese speaking countries" also reflects on the consequences of big data for Linguistics, and, more specifically, for multilingual countries that have Portuguese as their official language.

Given the variety of topics addressed and the backgrounds of the authors, I believe both the conference and the papers can be of the interest not only those who study information in their communities, but also to those who with their interactions shape their own field and others.

\section{References}

Dineen, J.D., (2017). Information research, practice, and education continue to invite and benefit from philosophy. Education for Information 33(1): 1-2. 
Floridi, L., (2002). On defining library and information science as applied philosophy of information. Social Epistemology 16(1): 37-49.

Herold, K. (Ed.), (2004). Philosophy of information [Special issue]. Library Trends 52(3).

Stallman, R.M., (2015). Free Software, Free Society: Selected Essays of Richard M. Stallman. Third Edition. Boston, MA: Free Software Foundation. 